\title{
Behavioral and social mechanisms behind pattern formation: an experimental study of animal movement
}

\author{
Erick M. G. Cordeiro • James F. Campbell • Thomas W. Phillips • \\ Kimberly A. With
}

Received: 30 January 2018/Accepted: 5 September 2018/Published online: 11 September 2018

(C) The Author(s) 2018

\begin{abstract}
Context Although animal movement behaviors are influenced by spatial heterogeneity, such behaviors can also generate spatial heterogeneity via interactions with the emergent spatial structure and other individuals (i.e., the social landscape).

Objective Elucidate the behavioral and ecological mechanisms of pattern formation in a homogeneous resource landscape.

Methods We analyzed the movement pathways and space-use patterns of the lesser grain borer (Rhyzopertha dominica) within homogeneous resource landscapes (wheat kernels). Experimental trials consisted
\end{abstract}

Electronic supplementary material The online version of this article (https://doi.org/10.1007/s10980-018-0713-1) contains supplementary material, which is available to authorized users.

E. M. G. Cordeiro $(\bowtie) \cdot$ T. W. Phillips

Department of Entomology, Kansas State University,

Manhattan, KS 66506, USA

e-mail: cordeiro.emg@gmail.com

J. F. Campbell ( $\square)$

Agricultural Research Service, Center for Grain and Animal Health Research, USDA, 1515 College Ave, Manhattan, KS 66502, USA

e-mail: james.campbell@ars.usda.gov

K. A. With

Laboratory for Landscape and Conservation Ecology, Division of Biology, Kansas State University, Manhattan, KS 66506, USA of individual beetles foraging alone or paired with a member of the same or different sex.

Results We identified two sources of pattern formation: (1) beetles were attracted to areas where they or another beetle had previously fed, leading to increased patchiness via positive reinforcement; and (2) the presence of conspecifics affected whether and at what scales patchiness occurred. Solitary males had lower rates of movement and less tortuous pathways than solitary females, but both sexes generated fine-scale patchiness in the resource distribution. Patchy resource landscapes were also generated by malefemale pairs, but not by same-sex pairings. Paired females in particular exhibited significantly greater daily net displacements and more random space use than solitary females.

Conclusions Pattern formation is a complex process, even in a relatively simple, homogeneous resource landscape. In particular, patterns created by individuals when foraging alone versus in pairs underscores how social interactions can fundamentally alter the resultant pattern of heterogeneity that emerges in resource landscapes.

Keywords Foraging - Rhyzopertha dominica . Insects · Heterogeneity · Resource patchiness · Fractal analysis · Ripley's L-function · Pattern-process linkage $\cdot$ Movement pathway 


\section{Introduction}

Understanding how animal movement is influenced by the environment, and how the environment in turn affects the spatial distribution of individuals, has important implications for the management and conservation of populations. Movement patterns reflect an animal's behavioral response to various chemical, physical, or biological stimuli within the environment (Able 1991; Patterson et al. 2008). Such movement responses also reflect the spatial and temporal scales at which species interact with the environmental heterogeneity (patchiness) of the landscape (Bond 1980; Loehle 1990; With and Crist 1995, 1996; Eccard and Liesenjohann 2008; Swihart et al. 2008; Fearer and Stauffer 2009; Lenz et al. 2015). The analysis of animal movement pathways can thus uncover how spatial heterogeneity influences an organism's movement and space use, and thus how landscape structure is perceived by a different species (With 1994a, b; Wiens 1995; Da Silveira et al. 2016; Ahearn et al. 2017). Spatial heterogeneity in turn can be identified by how organisms respond to the distribution of habitat or other resources on the landscape (i.e., functional heterogeneity; Kolasa and Rollo 1991; Li and Reynolds 1995), thereby illustrating the reciprocal nature of pattern and process.

Although the effects of resource patchiness on animal movement have received considerable study, particularly in landscape ecology, we know far less about how animal foraging behavior alters the patchiness of resource landscapes, especially in terms of how spatial heterogeneity might emerge within an initially homogeneous resource distribution. Within a homogeneous resource landscape, the interaction between foragers and their resource can give rise to increasing spatial heterogeneity over time (Utsumi et al. 2009). For example, predators may create areas of high and low prey density as they forage within a landscape (Fauchald et al. 2000; Russel et al. 2017), and herbivores can enhance the heterogeneity of their resource landscape through selective grazing of certain plant species or by preferentially grazing within certain areas of the landscape (Senft et al. 1987; Knapp et al. 1999). In some cases, the very act of foraging may increase the attractiveness of these areas causing foragers to return repeatedly, as when light grazing stimulates increased forage quality and production within "grazing lawns" or when plants or seeds damaged by feeding insects release volatile chemicals that signal the availability of a food source to other insects (Dowdy et al. 1993; Knapp et al. 1999; Launchbaugh and Howery 2005). Thus, foragers both create and respond to resource heterogeneity, creating feedbacks that can further reinforce patchiness in the landscape. In addition, interactions among the foragers themselves, whether positive (social or mate attraction) or negative (behavioral avoidance or agonistic interactions), can also influence pattern formation within resource landscapes (Franco and Harper 1988; Liao et al. 2015). We can thus anticipate that some combination of individual foraging behaviors and social interactions will influence resource heterogeneity and dynamics.

Elucidating the reciprocal and dynamic relationship between spatial patterns and ecological processes can be difficult, given that the spatiotemporal scales over which such interactions occur can make experimentation and hypothesis testing a challenge if conducted at traditionally defined landscape scales (Turner 1989, 2005). A useful research approach is therefore to develop appropriately scaled experimental model systems using small organisms, such as insects, to test hypotheses regarding mechanisms and develop insights into the nature of the interaction between pattern and process (Wiens and Milne 1989; Ims et al. 1993; Turner 2005). In that tradition, we developed an experimental system in which we explored how animal movement behavior can alternately give rise to and respond to spatial heterogeneity (patchiness) over time, and how this interaction is ultimately influenced by whether individuals were foraging alone versus in the presence of conspecifics (i.e., the influence of social interactions).

In our experimental system, we tracked and analyzed the movement pathways of a seed predator, Rhyzopertha dominica (lesser grain borer; Coleoptera: Bostrichidae), within an initially homogeneous resource landscape comprising a uniform layer of wheat grain. Rhyzopertha dominica exploits intact seeds as a food resource in natural ecosystems (Potter 1935; Wright et al. 1990), but is most commonly associated with anthropogenic stored-grain ecosystems where they colonize stored grain in bags and storage structures (Edde 2012) that are patchily distributed within the broader landscape. Stored grain is a relatively homogeneous resource patch that can be scaled down and simulated under laboratory 
conditions. As beetles feed on grain kernels, it is expected that they will create localized changes in the resource over time. However, it is unknown at what scales localized feeding behavior contributes to pattern formation, nor how the presence of conspecifics might modify movement and the subsequent development of spatial heterogeneity within the resource landscape. For species like $R$. dominica that use aggregation pheromones that affect the behavior of both sexes, interactions between conspecifics need not be direct to have an effect on movement behavior and resource utilization. Our experiments were thus designed to address the following questions: (1) over what scale does localized feeding behavior contribute to pattern formation in an initially homogeneous resource landscape, (2) how does the presence of conspecifics (another male or female) alter individual movement and feeding behaviors relative to when beetles are foraging in isolation, and (3) how does the social landscape (interactions with conspecifics) affect the development of spatial heterogeneity within a homogeneous resource landscape?

\section{Methods}

Experimental system

We used a $R$. dominica strain collected in rice fields in Otwell, Arkansas (July 2012), which had been cultured in the laboratory for $\sim 9$ generations before the start of experiments. Beetles were reared in 950-ml jars with $250 \mathrm{~g}$ of whole hard red winter wheat (Triticum aestivum), which was periodically sieved and a sub-sample of adults placed in fresh wheat, under constant environmental conditions $\left(28 \pm 1{ }^{\circ} \mathrm{C}\right.$ temperature, 14:10 L:D photoperiod, and $65 \pm 5 \%$ relative humidity).

We created a homogeneous resource landscape by spreading a monolayer of wheat kernels between two glass plates $(40 \mathrm{~cm} \times 20 \mathrm{~cm})$, with plates separated by plastic strips ( $1.5-\mathrm{cm}$ wide and $0.5-\mathrm{cm}$ thick) at the top and bottom edges so as to create a 5-mm gap to hold the wheat (Fig. 1a). The entire assembly was held together using four binder clips placed in pairs along the sides. Each resource landscape held $\sim 250 \mathrm{~g}$ of wheat kernels; a 5-cm space was left between the top of the grain and the top edge of the glass plates to simulate the surface of a grain mass. The dimensions of the resource landscape were sufficient for beetles to move freely within the gaps between kernels in both vertical and horizontal directions, as they do within a grain mass, while allowing beetle position and location of feeding damage to be observed through the glass (Cordeiro et al. 2016).

During experimental trials, the resource landscapes were placed vertically inside a box, and the top of the box was then covered with aluminum foil such that only the tops of the plates $(\sim 5 \mathrm{~cm})$ were above the foil (Supplemental Materials, Fig. 1). This enabled light to reach the top of the grain within the resource landscape, thereby simulating the light gradient that is typically found near the surface in a large grain mass (e.g., a storage bin). Fifteen plates (replicates) were set up at the same time in the box (experimental block), and a given experiment was repeated in two blocks (Supplemental Materials, Fig. 1). The experiments were conducted under constant environmental conditions (14:10 L:D photoperiod, $60 \%$ relative humidity, and $28^{\circ} \mathrm{C}$ ) in an incubator.

Observations of individual movement and space use

For all experiments, we focused on the movement behaviors of adults that had recently emerged from infested wheat kernels. Female grain borers deposit eggs on or near grain, and after hatching, the first instar larvae tunnel into a seed, where they develop to the adult stage before emerging 4-6 weeks later. Wheat kernels containing developing $R$. dominica were identified using $x$-ray pictures of the grain and collecting and holding infested kernels individually in glass vials (inner $\varnothing=13 \mathrm{~mm}$; height $=45 \mathrm{~mm}$ ) sealed with a cotton ball until adults were ready to emerge. Adults will chew a hole large enough to leave the kernel, but tend to remain inside the wheat kernel for a variable number of days before dispersing. During this pre-dispersal time, individual beetles were gently removed from the kernel and marked with a small dot of water-based ink on the pronotum (different colors were used to distinguish individuals when more than one beetle was used in an experiment). Marked beetles were then returned to the vial, and all re-entered the wheat kernel where they remained until the start of experiment. The process of determining the sex of an adult beetle can potentially injure the insect 
Fig. 1 a Example of feeding-site formation over time following the emergence of the lesser grain borer, Rhyzopertha dominica, from a wheat kernel within a

homogeneous resource landscape over a 28-day period. b Examples of the movement and feeding patterns created by a single female and by a single male in the resource landscape. Gray lines connect the beetle's daily position over the course of 28 days. Full black circles indicate the position of the infested kernel the beetle emerged from, and the open circles represent feeding sites created by the beetle. The different diameters of the feeding sites correspond to the relative sizes of patches produced by the beetle (a)

(1)

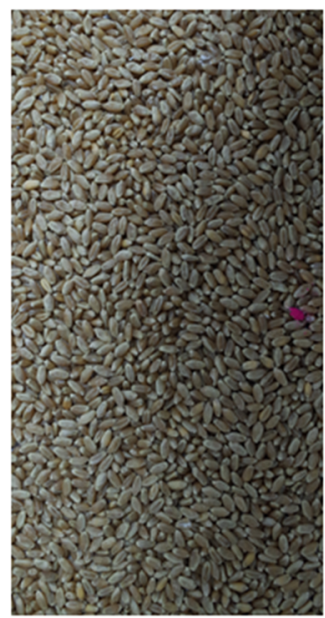

(2)

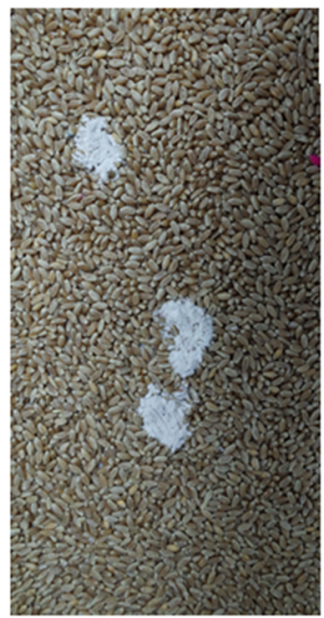

(3)

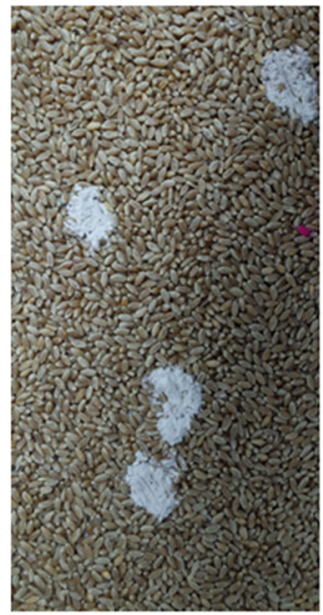

(b)

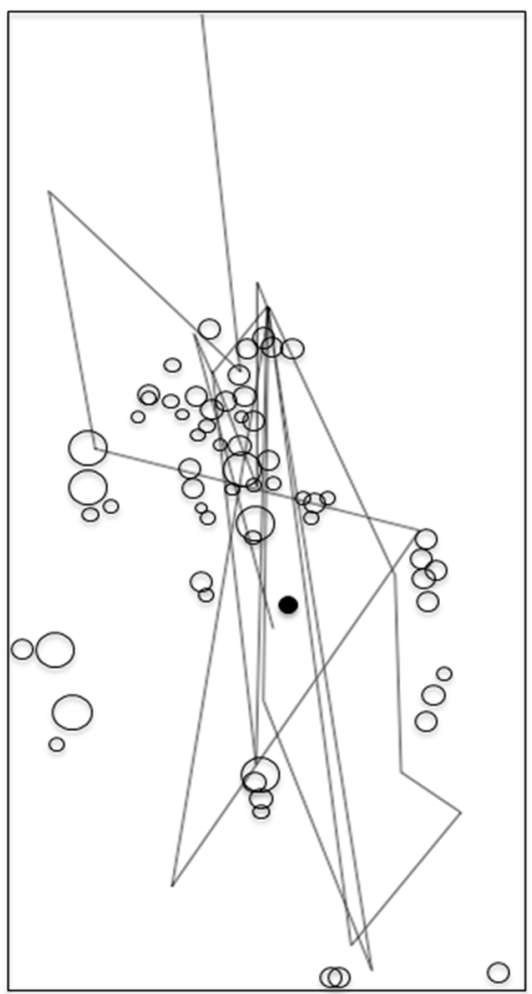

Male

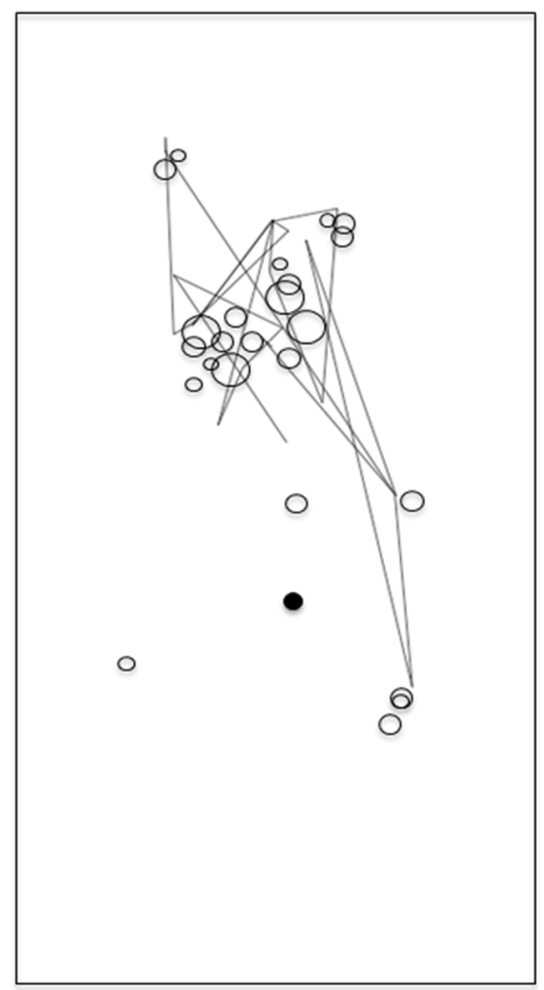

(Crombie 1941), so we did not assess the sex of individuals until the end of experiments.

Depending on the experiment, we either placed one kernel containing a marked adult at the center of the resource landscape (solitary-forager trials), or we positioned two kernels containing adults, which had been marked with different colors, spaced 10-cm apart horizontally along the center axis of the resource landscape (paired-forager trials). The sequential locations of each beetle were marked and numbered on the glass plate once each day for 28 consecutive days starting after the adult beetle left the kernel. Although 
the duration of the experiment represents a small fraction of $R$. dominica's life-span ( 240 days), it captures the most active phase (i.e., the first 2 weeks) allowing beetles to fully explore their environment without saturating it. At the end of each trial, we photographed the glass plates with the marked beetle positions and then imported the digital images into the image-processing software, Image ${ }^{\circledR}$, which we used to measure the distances and angles between the sequential locations for each beetle to derive the individual's movement pathway. In addition to movement pattern, we also characterized the feeding sites created by beetles over the course of each experimental trial. When feeding on wheat, $R$. dominica create visible accumulations of flour and frass, thus generating heterogeneity (patchiness) within the initially homogeneous landscape (Fig. 1a). The number and size of these feeding sites were evaluated from the digital images of the plates. The size of feeding sites was calculated as the area of a circle that completely circumscribed each feeding site (Fig. 1b).

Spatial analysis of movement pathways and spaceuse patterns

For each beetle, we calculated the daily net displacement and tortuosity of its movement pathway. Daily net displacement $(\mathrm{cm})$, the straight-line distance traveled in a 24-h period, was obtained for each individual in treatments with a solitary male, a solitary female, and in pairs of the same or opposite sex. Tortuosity refers to how convoluted the movement pathway is and can be assayed by calculating the fractal dimension $(D)$ of the pathway (With 1994a, b). For movement in two dimensions, the fractal dimension varies between $D=1$, in which the pathway is a straight line, and $D=2$, in which the pathway is so convoluted as to cover the entire plane (With 1994a, b; Nams and Bourgeois 2004). Animal movement pathways are typically more convoluted than a straight line but not so convoluted as to fill a plane, and so will have a "fractional" (fractal) dimension (e.g., $D=1.2$; With 1994a, b). Although animal movement patterns may not exhibit the same fractal dimension over all scales (i.e., the metric exhibits scale-dependence; Benhamou 2004), we are calculating $D$ over a small range of scales and are using this in conjunction with daily net displacement as a descriptive measure of movement (i.e., we are not attempting to extrapolate movement patterns to other scales). To compare tortuosity of movement among treatments, we estimated $D$ for solitary males and females, and for pairs of beetles of the same or different sex, using the software, Fractal (Nams 1996). Movement was so limited in some males ( $n=6$ ) that we were unable to calculate $D$, and thus these individuals were excluded from all analyses (Caldwell and Nams 2006). Differences among groups were analyzed with an ANOVA design using type III sums of squares to measure the overall effect, which we followed with post hoc comparisons of significant effects using Tukey's HSD test. The analyses were performed using SAS version 9 software (SAS Institute, Cary, NC). All data are presented as mean \pm SEM. For the single-beetle trials, we ended up with 20 replicates for males and 18 replicates for females (recall that beetles were sexed at the end of trials). For the paired-forager trials, we had 16 female-female pairs, 6 male-male pairs, and 15 male-female pairs.

Because beetles did not feed at every location where they were found, we ended up analyzing the spatial patterns of the movement locations separately from the distribution of feeding sites so as to gain additional insight into the movement and foraging behavior of these beetles. To determine whether movement and space-use patterns created by solitary beetles were random, clumped, or overdispersed, we analyzed the resultant spatial patterns using Ripley's L-function for each separately (Ripley 1988). Like many spatial statistics, Ripley's L-function assumes stationarity, and furthermore, that a stochastic point process is responsible for the observed spatial point pattern. The point-location data for beetle locations and feeding sites are ultimately generated by a continuous movement process, however. As a result, animal movements tend to be correlated over short distances, and thus are likely to generate a more clumped distribution of locations at finer spatial scales than a stochastic point process. We thus approached this analysis more from the standpoint of a null hypothesis (i.e., the pattern expected if the locations were created by a stochastic point process). Given that we know that these locations were the product of a continuous movement process, however, we also compared the point-pattern distribution of beetle locations to those generated by a correlated random walk (CRW), which provides a better model of the underlying spatial process that generated the beetle location data. Although our approach here to 
analyzing animal movement locations as a spatial point pattern is unconventional, we believe that it at least enables us to make some inferences about the pattern of beetle locations and feeding sites, especially as beetle movements were not recorded continuously over the 28-day observation period. Furthermore, the characterization of individual beetle locations using the Ripley's L-function facilitated comparisons with the joint occurrence of pairs of beetles that were analyzed using the multi-type K-function to be described later.

To generate the expected spatial point patterns of beetle locations assuming a continuous movement process, we simulated CRWs using a Weibull distribution of step-lengths and Wrapped-Cauchy $(\mu=0)$ turning angles using the 'Circular' package in R. Based on the observed data, a maximum-likelihood function was used to find best-fit values for the Weibull distribution parameters shape and scale based on each observed path using fitdist function available in the package MASS in R (Supplemental Materials, Appendix I). The shape ( $\mu=4.6, \sigma=3.2)$ and scale $(\mu=9.8, \sigma=4.2)$ used in the simulations were sampled from a normal distribution at every iteration during the simulation. The number of steps in each simulation path were also sampled from a normal distribution ( $\mu=18.1, \sigma=7.7)$ based on the mean and standard deviation calculated from the observed data (i.e., beetles did not always move to a new location every day, but on average moved 18 times during the 28-day observation period). We also varied the concentration parameter of the circular distribution ( $r h o$ ) to be $0.2,0.4$, or 0.6 , where 0.2 produces a more tortuous pathway and 0.6 produces a more linear pathway. These rho values were thus selected to encompass a range of movement patterns that might be generated by real beetles (i.e., from near-linear pathways to pathways of greater tortuosity). We performed 30 repetitions ( $n=30 \mathrm{CRWs})$, obtained the point coordinates for each of the simulated pathways, and then analyzed the resulting spatial patterns using Ripley's L function.

The method of characterizing patterns based on the L-function is the same for both beetles and simulated CRWs. The L-function is a standardized version of Ripley's K-function, which uses all point-to-point distances between locations (feeding sites or beetle positions) to describe two-dimensional distribution patterns. A circle of radius $r$ is centered on each point (beetle location) and the number of neighboring points within the circle are counted and compared to an expected value $(\lambda \mathrm{K}(r))$ generated under a Poisson distribution $\left(\pi r^{2}\right)$; the procedure is then repeated for circles of increasing radii (Haase 1995). The K-functions were generated using the khat function in the $\mathrm{R}$ package 'splancs' (R Core Team 2014). The L-functions were derived from the $\mathrm{K}$-function using the transformation $\mathrm{L}(r)=\sqrt{\mathrm{K}(r) / \pi}-r$, where $r$ is the radius or distance scale (Rowlingson and Diggle 2013).

The L-function curves fitted to the beetle and simulated CRW locations were then each compared to the Poisson reference curves, which gives the expectation for a random distribution. If the fitted curve fell within the bounds of the $95 \%$ acceptance envelope of the reference curve at different scales (distances, $r$ ), the spatial distribution of sites was considered to be random (Haase 1995). If the deviation of the fitted curve from the reference curve was above the upper limit of the $95 \%$ acceptance envelope, the distribution was clumped. If the deviation from expected was below the lower limit of the $95 \%$ acceptance envelope, the distribution was overdispersed (regular or uniform). We used the Kenv.csr function in the $\mathrm{R}$ 'splancs' package to generate the acceptance envelopes based on 100 simulations for each curve. Because of the large number of L-function diagrams generated, we evaluated the overall response based on the frequency of beetles in a given experiment that exhibited clumped, random or overdispersed patterns of movement or space use (feeding sites) at each scale (i.e., the distance $r$ at which the pattern was assessed) (Supplemental Materials, Appendix II).

For the paired-forager trials, we evaluated the degree of association between the movements of beetle pairs using the multi-type K-function, which counts the expected number of observed locations of the second insect within a given distance of the observed locations of the first insect (Harkness and Isham 1983). The multi-type K-function was evaluated as described above for the L-function of single beetles to help us understand the associated movements of beetle pairs, in terms of whether the locations of the two individuals tended to be clumped (positive association between individuals), random (no association), or overdispersed (negative association), and 
how the degree of association may have changed as a function of scale.

\section{Patch-choice experiments}

Based on the data obtained in this study and in Cordeiro et al. (2016), individual $R$. dominica were often observed near previous feeding sites, and occasionally returned to the kernel from which they had emerged, suggesting that they recognize-and perhaps prefer-sites where they have previously foraged. This behavioral response could generate spatial pattern via positive reinforcement. To evaluate this, we performed two patch-choice experiments to evaluate (1) beetle preference for wheat from their own feeding sites compared to wheat from nonfeeding sites, and (2) beetle preference for their own feeding sites compared to wheat from feeding sites created by another individual.

We collected the beetles, along with 5-g samples of wheat from within feeding sites and from non-feeding sites, from the resource landscapes used in the experiments described above; the patch-choice experiments were initiated the same day (Supplemental Materials, Fig. 1). Each beetle was used in both patchchoice tests. The wheat samples were placed in individual Petri dishes $(35 \mathrm{~mm} \times 10 \mathrm{~mm})$ in which six equidistant openings $(\varnothing=3 \mathrm{~mm})$ had been drilled in the sides at the base of the dish right at the bottom to allow beetles to enter and exit dishes. The dishes were placed on opposite sides of a square Petri dish $(9 \mathrm{~cm} \times 9 \mathrm{~cm})$. The bottoms of the square Petri dishes were covered with discs of filter paper, affixed using water-based white (synthetic) glue resin to facilitate walking, and the inner walls were coated with Teflon PTFE (DuPont, Wilmington, DE, USA) to prevent beetles from climbing up the sides.

Individual beetles were placed at one of the empty corners of the square Petri dish (one beetle/replication $\times 30$ beetle replicates/treatment). Choice tests were run for $24 \mathrm{~h}$ under constant environmental conditions (dark conditions, $30 \pm 1{ }^{\circ} \mathrm{C}$, and $65 \pm 0 \%$ relative humidity). Beetle patch choice was based on which dish the beetle was in at the end of the trial. Data were analyzed using a binomial test procedure to evaluate if the frequency of choice was non-random.

\section{Results}

What is the innate movement and space-use patterns of beetles within a homogeneous resource landscape?

Solitary females were about twice as mobile $(\bar{x}=7.2 \pm 0.6 \mathrm{~cm} /$ day, $n=18)$ as solitary males $\left(\bar{x}=3.7 \pm 0.9 \mathrm{~cm} /\right.$ day, $\quad n=14 ; \quad F_{1,36}=11.70$; $P<0.001$; Fig. 2a). Movement path tortuosity was also significantly different between sexes $\left(F_{5,68}=3.51, P<0.007\right.$; Fig. $\left.2 b\right)$. Females had a more tortuous path (fractal $\bar{D}=1.4 \pm 0.0, n=18$ ) than males $\left(\bar{D}=1.2 \pm 0.0, n=14 ; F_{1,36}=16.01\right.$; $P<0.003$; Fig. 2b).
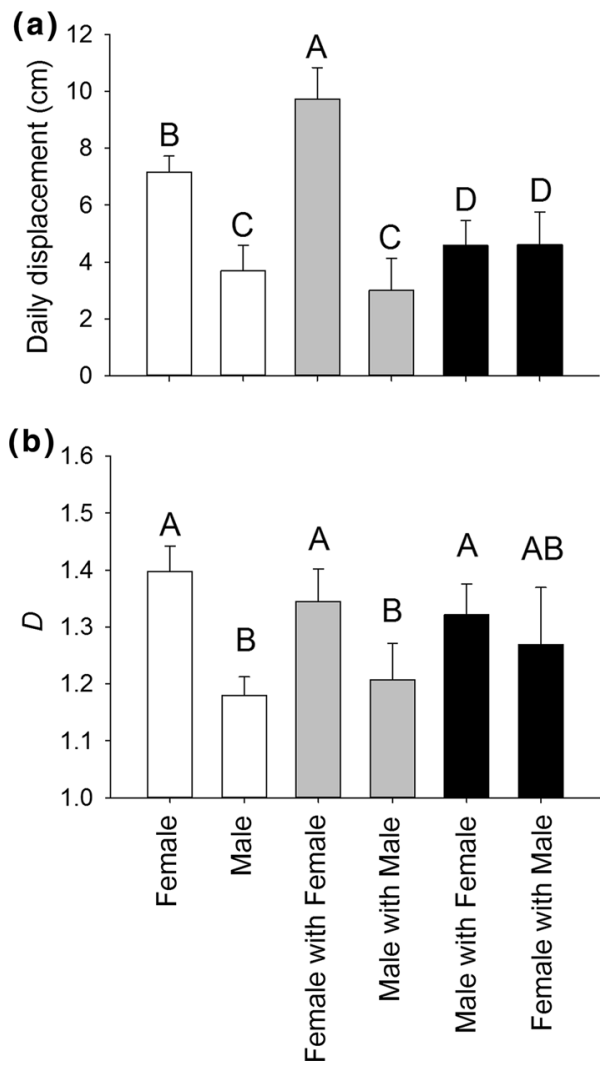

Fig. 2 a Daily net displacement $(\bar{x} \pm \mathrm{SE})$ by Rhyzopertha dominica as a function of sex and the presence of conspecifics $\left(F_{5,68}=6.55, P<0.001\right.$, ANOVA $)$. b Fractal dimension $(\bar{D} \pm \mathrm{SE})$ of $R$. dominica movement pathways as a function of sex and the presence of conspecifics $\left(F_{5,68}=3.51, P<0.007\right.$, ANOVA). Tukey's Studentized Range (HSD) test was used for post hoc comparisons among groups, with different letters above bars indicating significant differences $(\alpha=0.05)$ 
The spatial distribution of both males and females and their feeding sites was dependent on the spatial scale over which they were evaluated (Fig. 3): distributions were predominantly clumped over a short range $(<15 \mathrm{~cm})$ and predominantly random at the broadest scale $(20 \mathrm{~cm})$ of analysis. Males and females exhibited a similar pattern of response, but differed in the distances over which they switched from a clumped to random spatial pattern. The transition from a clumped to random distribution occurred between 17 and $18 \mathrm{~cm}$, but appeared to be happening a bit sooner for males than females. At $20 \mathrm{~cm}$, male movement locations exhibited a predominantly (90\%) random distribution, with females showing more of a mixed pattern at this scale, albeit more random (62\%) than clumped. Space-use patterns (the pattern of feeding sites) revealed a similar response, which underscores that beetle movement and feeding sites are correlated, even though beetles did not feed at every location where they were found. The transition from a clumped to random distribution for feeding sites occurred between 15 and $17 \mathrm{~cm}$, with $>80 \%$ of both males and females exhibiting a random distribution at the $20-\mathrm{cm}$ scale.
A marked difference in the pattern of distribution was observed between the paths generated by the simulated CRWs and the observed beetles' paths (compare Figs. 3 and 4). The movement locations of the simulated CRWs started out predominantly random and became clumped only at intermediate scales. Simulated pathways with rho $=0.2$ exhibited a greater proportion of clumped distributions starting at $6 \mathrm{~cm}$ and continuing to the maximum distance of $20 \mathrm{~cm}$, whereas for larger rho values of 0.4 and 0.6 , the proportion of clumped distributions peaked between 5 and $10 \mathrm{~cm}$ and started to decline after $18 \mathrm{~cm}$. In contrast, movement locations of beetles started out as predominantly clumped and became random only at broader scales (e.g., 17-18 cm). Beetle movements are thus more clumped than expected by a CRW at most scales examined here, but especially at finer spatial scales.

How does the presence of a conspecific alter an individual's movement behavior and space-use patterns?

The social landscape had a significant effect on daily net displacement $\left(F_{5,68}=6.55, P<0.001\right.$; Fig. 2a $)$.
Fig. 3 Scale-dependent movement and space-use patterns of male and female Rhyzopertha dominica. The assessment of spatial pattern at each scale is based on the percentage of beetles that exhibited either a random or clumped distribution at a given distance class, which was determined from the individual analyses of Ripley's L-function for each beetle's space-use patterns
Males
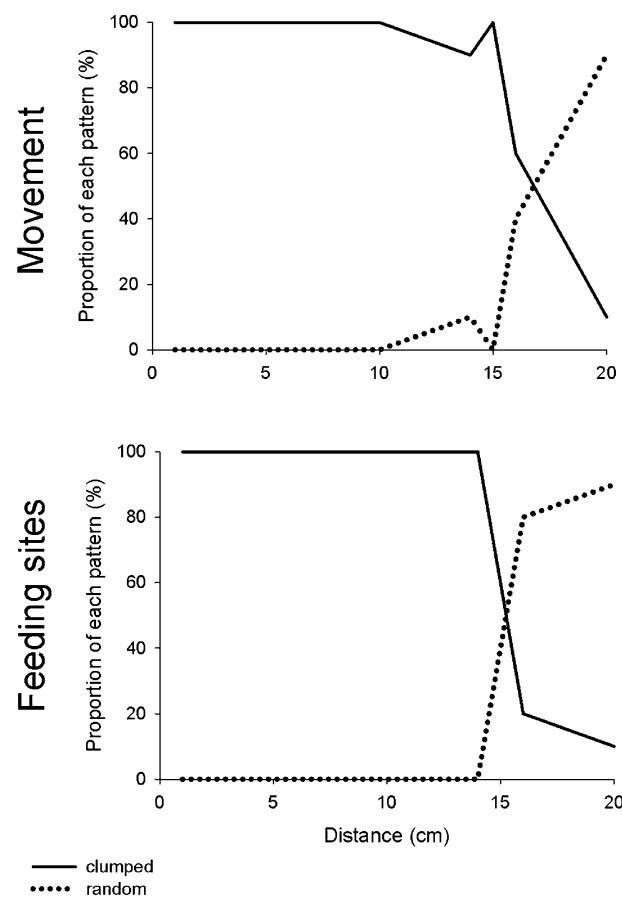

Females
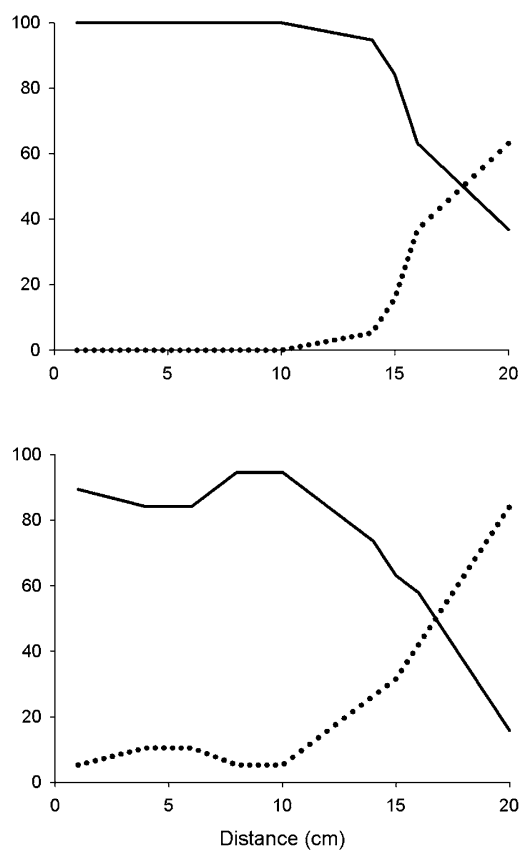
simulated rho 0.2

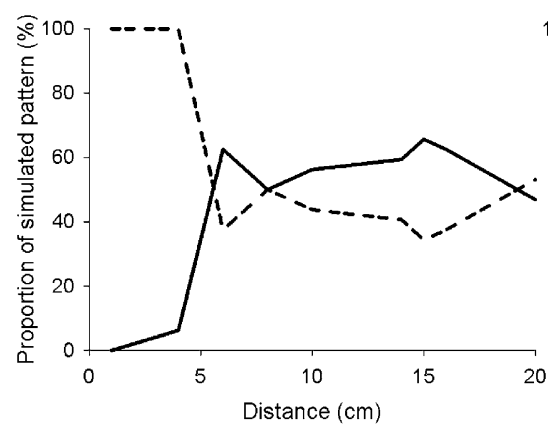

clumped
- c
random

Fig. 4 Expected scale-dependence in the distribution of movement locations for a series of simulated correlated random walks $(n=30)$ for three different values of rho. The resulting spatial pattern is represented as the percentage of simulated

The presence of another female significantly increased female daily net displacement, and this combination had the highest displacement of any pairing $(\bar{x}=9.7 \pm 1.1 \mathrm{~cm} /$ day, $n=8, P<0.001 ;$ Fig. $2 \mathrm{a})$. Males alone or paired with another male did not differ significantly in daily net displacement $(P=0.681)$. Males in the presence of a female $(\bar{x}=4.6 \pm 1.2 \mathrm{~cm} /$ day, $n=9)$ or females in the presence of a male $(\bar{x}=4.6 \pm 0.9 \mathrm{~cm} /$ day, $n=9)$ were intermediate in displacement and did not differ significantly from each other $(P=0.984$; Fig. $2 \mathrm{a})$.

Path tortuosity for females $(\bar{D}=1.4 \pm 0.0, n=18)$ was not significantly affected by the presence of another female $(\bar{D}=1.4 \pm 0.0, n=8, P=0.50)$ or by a male $(\bar{D}=1.5 \pm 0.1, n=9 ; P=0.43)$. The presence of a female significantly increased the path tortuosity of males $(\bar{D}=1.3 \pm 0.1, \quad n=9$, $P<0.001$ ), however, indicating that males detected the presence of females and changed their movement paths in response, becoming more similar to female movements (Fig. 2b). There was no significant difference in the tortuosity of male movement pathways when paired with another male $(\bar{D}=1.2 \pm 0.1, n=5$, $P=0.78$ ).

When beetles were with another individual of the same sex, individuals maintained an average distance of $12.3 \pm 1.1 \mathrm{~cm}$ in the case of paired females $(n=9)$ or $11.1 \pm 1.0 \mathrm{~cm}(n=9)$ for paired males; these distances were not significantly different $(n=19$, $P=0.53)$. However, individuals were $2 \mathrm{x}$ closer when walkers that exhibited either a random or clumped distribution at a given distance class, which was assessed from the individual analyses of Ripley's L-function for each space-use pattern

paired with an individual of the opposite sex $\left(\bar{x}=5.4 \pm 1.0 \mathrm{~cm}, n=9, F_{2,25}=11.45, P<0.001\right)$.

The space-use patterns (feeding sites) of males and females were affected by the presence of individuals of the opposite sex (Fig. 5). When paired with a member of the opposite sex, individuals exhibited a more clumped (patchy) distribution at most distances, with the greatest degree of clumping occurring at intermediate scales $(10-15 \mathrm{~cm})$. This is in contrast to the generally random pattern of space use exhibited by females when paired with another female, and by males when paired with another male (Fig. 5). The only exception was at distances $<10 \mathrm{~cm}$, where nearly $20 \%$ of males exhibited a clumped distribution, suggesting that males were interacting at close range.

Patch-choice experiments

Regardless of sex, beetles showed a strong preference for wheat collected from feeding sites rather than from non-feeding sites $(86.4 \%$ vs. $13.6 \%$, respectively, $z=3.4, P<0.001, n=22$ ). This preference was not specific to their own feeding sites, as there was no significant difference in their preference for wheat obtained from their own feeding site versus wheat from another individual's feeding site $(45 \%$ vs. $55 \%$, respectively; $z=-0.89, P=0.37, n=20$ ). Beetles preferred feeding-site patches regardless of whether it was produced by a beetle of the same or opposite sex $\left(F_{3,16}=0.44, P=0.73\right)$. 
Two females

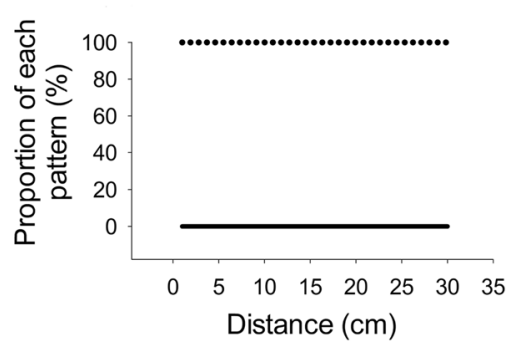

$\begin{array}{ll}\text { clumped } \\ \ldots \ldots . . & \text { random }\end{array}$

Fig. 5 Effect of conspecifics on space-use patterns in Rhyzopertha dominica. The resulting spatial pattern is represented as the percentage of beetles that exhibited either a random or clumped distribution at a given distance class, which was

\section{Discussion}

Our study demonstrates how an animal's movement patterns and interactions with the resource landscape, as well as with other individuals within that landscape, can lead to the formation of spatial heterogeneity within an initially homogeneous resource. Our findings on the movement and feeding behaviors of $R$. dominica indicate the existence of at least two, nonmutually exclusive mechanisms that contribute to pattern formation. First, individuals interact with their habitat by feeding and creating patchiness, which then affects subsequent beetle movements and space use. In this case, feeding sites (created either by themselves or another beetle) were more attractive to foraging individuals than sites where feeding had not yet occurred, causing individuals to return to the same areas of the landscape. The mechanisms behind this pattern have not yet been fully elucidated, but could be related to either greater ease of movement within disturbed areas of the resource landscape (e.g., cleared areas around feeding sites), chemical cues that signal the availability of a food resource (i.e., damaged wheat kernels), and/or to social facilitation by the beetles themselves (pheromone production related to mate attraction). Our patch-choice experiment suggests that beetles are primarily using chemical cues to locate patches, but whatever the reason, the higher attractiveness of feeding sites created a positive feedback that reinforced patchiness.

Second, individuals altered their movement behavior in the presence of other beetles, but the nature of assessed from the individual analyses of Ripley's L-function for each beetle space-use pattern for a given type of pairing (paired males, paired females, and male-female pairs)

their movement response depended on the sex of those conspecifics. The presence of conspecifics could have either an antagonistic effect on movement, as when females increased their daily net displacement rate in the presence of another female, or a positive effect, as when male shifted their movements to match that of females. We explore the effect of the social landscape on pattern formation in greater detail below.

Most previous research on animal movement has examined how solitary individuals respond to environmental heterogeneity (e.g., Crist et al. 1992; With 1994a, b; Etzenhouser et al. 1998; Frair et al. 2005). The movement patterns generated by individuals in isolation might thus be interpreted as that species' "default" behavior that they exhibit upon the initial colonization and exploration of a new landscape (Lima and Zollner 1996), especially in the context of our study in which solitary beetles were introduced to a homogeneous resource landscape (i.e., before their foraging activities created patchiness in the landscape and in the absence of conspecifics that might alter their behavior). In our system, solitary male and female beetles exhibited fundamentally different movement behaviors, demonstrating an intrinsic source of sexual variation in behavior that can potentially modulate the way they interact with their environment. This sort of variation and its ecological and evolutionary implications are generally underestimated and under-represented in the literature (Sih et al. 2004).

Intersexual differences in movement may come about primarily because of different mate-finding strategies in males versus females (Gehrt and Fritzell 
1997). After emerging within a homogeneous resource landscape, solitary female beetles in our study exhibited a more complex movement pathway than males, which is likely an indicator of a more intensive localized search associated with microhabitat selection (Caldwell and Nams 2006; Nams 2006a, b). In the case of unmated females, this is possibly associated with the search for males. Rhyzopertha dominica males are known to produce an aggregation pheromone, to which both females and males respond (Khorramshahi and Burkholder 1981; Williams et al. 1981). Males may move less because releasing pheromone from fixed locations can increase the ability of females to locate males, and since feeding is directly correlated with pheromone production (Bashir et al. 2003), they tend to have fewer and larger feeding sites than females (Cordeiro et al. 2016). This could also reflect an energetic trade-off between the cost of pheromone production versus the energetic costs of moving, especially as solitary males had lower rates of movement and less tortuous pathways than solitary females and only changed their movement strategy upon detecting a female.

An animal can respond differently to its environment at different spatial scales, signifying different domains of scale, in which case the structure of its movement path is predicted to change from one domain to another (Wiens et al. 1993). The spatial distribution of beetle movement locations and feeding sites are scale-dependent, with only small differences apparent in the scaling domains of males versus females. Under the assumption of a correlated random walk (CRW), the distribution of individual movement or feeding-site locations was expected to be random initially, shifting to a clumped distribution only at intermediate scales, as determined by the rho parameter (i.e., the proportion of simulated CRWs exhibiting a clumped distribution at intermediate scales increased at lower rho values). By contrast, beetle movement and feeding-site locations started out clumped and exhibited a random distribution only at broader scales $(17-18 \mathrm{~cm})$. Thus, beetle movement and space-use patterns are more clumped than expected under the assumption of a CRW, likely because beetle search behavior is influenced by stimuli differently at different scales. For example, an attraction to previous feeding sites may contribute to positive reinforcement that leads to a clumped distribution at a local scale $(\leq 15 \mathrm{~cm})$, perhaps because the concentration of volatile cues associated with these areas decays with distance, causing beetles to exhibit more random movements outside these areas. That beetles can perceive and orient toward resource patches from a distance has been widely demonstrated in insects, although their perceptual range can be modified by patch size and quality (large patches or patches of high resource abundance may be easier to detect), as well as by the direction of air currents (e.g., Schooley and Wiens 2003; Romero et al. 2010). Thus, the distribution and concentration of chemical cues provides an additional source of heterogeneity in these landscapes to which beetles respond.

Individuals are not just interacting with the resource landscape, however; they are also interacting with each other (the social landscape) (Russel et al. 2015). Our results demonstrate that the presence of a conspecific can have a significant effect on movement and space use, depending on the type of pairing. In the presence of another female, for example, female beetles significantly increased their rate of daily net displacement. It is not clear what cues they used to detect the presence of other females, however, since only males have been reported to produce pheromones (Williams et al. 1981). By contrast, the presence of another male did not significantly affect the overall movement of males, except over short distances $(<10 \mathrm{~cm})$, where their joint distribution actually became more clumped (i.e., more positively associated with one another). The response of males to other males appears to be a fairly localized response, perhaps due to male-produced aggregation pheromone (Williams et al. 1981; Dowdy et al. 1993).

When males were paired with a female in these resource landscapes, however, the tortuosity of the male's movement pathway increased relative to solitary males or males paired with another male. This suggests that they detected the presence of the female, and furthermore, changed their movement and spaceuse pattern to one more similar to females (i.e., they were following females). This could be due to males switching from a sit-and-wait strategy to an activesearch strategy when females were detected, for example. Our results thus demonstrate how differences in the social environment can also contribute to differences in resource utilization within a landscape.

In conclusion, our findings illustrate how movement and foraging behaviors within a simple, homogeneous resource landscape can contribute to the 
formation and maintenance of spatial heterogeneity. Using an experimental model system based on a ubiquitous seed predator, the lesser grain borer $(R$. dominica), which typically inhabits homogeneous resource environments (e.g., grain storage bins), we show how spatial heterogeneity can be generated through a combination of individual movement behaviors, interactions with other conspecifics, and interactions with the increasing heterogeneity of the environment. Patches emerge through localized feeding behaviors and subsequent feeding-site modifications by beetles. A preference for previously exploited patches leads to patch enlargement and a concentrated pattern of space-use across the landscape. Pattern formation is further modified or enhanced through interactions with conspecifics (i.e., the social landscape), involving either individual attraction (femalemale interactions) or avoidance (same-sex interactions), which manifest in different movement behaviors and patterns of space use. The reciprocal nature of the interaction between animal movement and spatial pattern is thus complex, even within a relatively simple experimental system.

Our experimental system shares certain similarities with grazing systems: both provide an abundant resource in which the forager is basically immersed in its resource, and whose foraging behavior creates localized areas of disturbance (foraging sites or grazing lawns) that enhance resource heterogeneity, which then influence future foraging decisions and space use over the broader landscape. Large herbivores such as native grazers and domestic livestock are well-known examples of such grazing systems, where concentrated foraging within preferred areas contribute to greater heterogeneity in grasslands (Knapp et al. 1999; Launchbaugh and Howery 2005; Allred et al. 2011). In addition to their foraging activities, large mammals also deposit urine and manure, which can further enhance forage quality, especially in systems where nitrogen is limited and/or fires are frequent (fire results in the volatilization or loss of nitrogen) (Knapp et al. 1999; Augustine 2003). Thus, despite some similarities to our experimental system, grazing systems are not really homogeneous, especially as grazing interacts with other disturbances, such as fire, as well as existing environmental or topoedaphic gradients to create a heterogeneous and dynamic resource landscape. Nevertheless, the advantage of our experimental system is that we can explore mechanistically how foraging behaviors in different social contexts first give rise to pattern, thus offering a complementary perspective to traditional studies of landscape effects on animal movement, where the focus has been on understanding how landscape pattern influences movement behavior.

Acknowledgements We thank R. Hammel and A. Redmon for excellent technical support and the Brazilian National Council of Scientific and Technological Development (CNPq) for financial support. Mention of trade names or commercial products in this publication is solely for the purpose of providing specific information and does not imply recommendation or endorsement by the U. S. Department of Agriculture or Kansas State University. USDA is an equal opportunity employer. This paper is contribution number 16-335-J of the Kansas Agricultural Experiment Station.

Open Access This article is distributed under the terms of the Creative Commons Attribution 4.0 International License (http:// creativecommons.org/licenses/by/4.0/), which permits unrestricted use, distribution, and reproduction in any medium, provided you give appropriate credit to the original author(s) and the source, provide a link to the Creative Commons license, and indicate if changes were made.

\section{References}

Able KP (1991) Common themes and variations in animal orientation systems. Am Zool 31:157-167

Ahearn S, Dodge S, Simcharoen A, Xavier G, Smith JLD (2017) A context-sensitive correlated random walk: a new simulation model for movement. Int J Geogr Inf Sci 31:867-883

Allred BW, Fuhlendorf SD, Hamilton RG (2011) The role of herbivores in Great Plains conservation: comparative ecology of bison and cattle. Ecosphere 2:1-17

Augustine DJ (2003) Long-term, livestock-mediated redistribution of nitrogen and phosphorus in an East African savanna. J Appl Ecol 40:137-149

Bashir T, Birkinshaw LA, Farmn D, Hall DR, Hodges RJ (2003) Pheromone release by Rhyzopertha dominica (F.) (Coleoptera: Bostrichidae) in the laboratory: daily rhythm, inter-male variation and association with body weight and/ or boring activity. J Stored Prod Res 39:159-169

Benhamou S (2004) How to reliably estimate the tortuosity of an animal's path: straightness, sinuosity, or fractal dimension? J Theor Biol 229:209-220

Bond AB (1980) Optimal foraging in a uniform habitat: the search mechanism of the green lacewing. Anim Behav 28:10-19

Caldwell IR, Nams VO (2006) A compass without a map: tortuosity and orientation of eastern painted turtles (Chrysemys picta picta) released in unfamiliar territory. Can J Zool 84:1129-1137

Cordeiro EMG, Campbell JF, Phillips TW (2016) Movement and orientation decision modeling of Rhyzopertha 
dominica (Coleoptera: Bostrichidae) in the grain mass. Environ Entomol 45:410-419

Crist TO, Guertin DS, Wiens JA, Milne BT (1992) Animal movement in heterogeneous landscapes: an experiment with Eleodes beetles in shortgrass prairie. Funct Ecol 6:536-544

Crombie AC (1941) On oviposition, olfactory conditioning and host selection in Rhyzopertha dominica Fab. (Insecta, Coleoptera). J Exp Biol 18:62-79

Da Silveira NS, Niebuhr BBS, de Muylaert RL, Ribeiro MC, Pizo MA (2016) Effects of land cover on the movement of frugivorous birds in a heterogeneous landscape. PLoS ONE 11:e0156688

Dowdy AK, Howard RW, Seitz LM, McGaughey WH (1993) Response of Rhyzopertha dominica (Coleoptera: Bostrichidae) to its aggregation pheromone and wheat volatiles. Environ Entomol 22:965-970

Eccard JA, Liesenjohann T (2008) Foraging decisions in riskuniform landscapes. PLoS ONE 3:e3438

Edde P (2012) A review of the biology and control of Rhyzopertha dominica (F.) the lesser grain borer. J Stored Prod Res 48:1-18

Etzenhouser M, Owens MK, Spalinger DE, Murden SB (1998) Foraging behavior of browsing ruminants in a heterogenous landscape. Landscape Ecol 13:55-64

Fauchald P, Erikstad KE, Skarsfjord H (2000) Scale-dependent predator-prey interactions: the hierarchical spatial distribution of seabirds and prey. Ecology 81:773-783

Fearer TM, Stauffer F (2009) Relationship of ruffed grouse (Bonasa umbellus) home range size to landscape characteristics. Am Midl Nat 150:104-114

Frair JL, Merrill EH, Visscher DR, Fortin D, Beyer H, Morales JM (2005) Scales of movement by elk (Cervus elaphus) in response to heterogeneity in forage resources and predation risk. Landscape Ecol 20:273-287

Franco M, Harper JL (1988) Competition and the formation of spatial pattern in spacing gradients: an example using Kochia scoparia. J Ecol 76:959-974

Gehrt SD, Fritzell EK (1997) Sexual differences in home ranges of raccoons. J Mammal 78:921-931

Haase P (1995) Spatial pattern analysis in ecology based on Ripley's K-function: introduction and methods of edge correction. J Veg Sci 6:575-582

Harkness R, Isham V (1983) A Bivariate spatial point pattern of ants' nests. J R Stat Soc 32:293-303

Ims RA, Rolstad J, Wegge P (1993) Predicting space use responses to habitat fragmentation: can voles Microtus oeconomus serve as an experimental model system (EMS) for capercaillie grouse Tetrao urogallus in boreal forest? Biol Conserv 63:261-268

Khorramshahi A, Burkholder WE (1981) Behavior of the lesser grain borer, Rhyzopertha dominica (Coleoptera: Bostrichidae) male-produced aggregation pheromone attracts both sexes. J Chem Ecol 7:33-38

Knapp AK, Blair JM, Briggs JM, Collins SL, Hartnett DC, Johnson LC, Towne EG (1999) The keystone role of bison in North American tallgrass prairie. Bioscience 49:39-50

Kolasa J, Rollo CD (1991) Introduction: the heterogeneity of heterogeneity: a glossary. In: Kolasa J, Pickett STA (eds) Ecological heterogeneity. Springer, New York, pp 1-23
Launchbaugh KL, Howery LD (2005) Understanding landscape use patterns of livestock as a consequence of foraging behavior. Rangel Ecol Manag 58:99-108

Lenz J, Böhning-Gaese K, Fiedler W, Mueller T (2015) Nomadism and seasonal range expansion in a large frugivorous bird. Ecography 38:54-62

Li H, Reynolds JF (1995) On definition and quantification of heterogeneity. Oikos 73:280-284

Liao J, Bogaert J, Nijs I (2015) Species interaction determines the spatial mortality patterns emerging in plant communities after extreme events. Nature 5:11229

Lima S, Zollner P (1996) Towards a behavioral ecology of ecological landscapes. Trends Ecol Evol 11:131-135

Loehle C (1990) Home range: a fractal approach. Landscape Ecol 5:39-52

Nams VO (1996) The VFractal: a new estimator for fractal dimension of animal movement paths. Landscape Ecol 11:289-297

Nams VO (2006a) Animal movement rates as behavioural bouts. J Anim Ecol 75:298-302

Nams VO (2006b) Detecting oriented movement of animals. Anim Behav 72:1197-1203

Nams VO, Bourgeois M (2004) Fractal analysis measures habitat use at different spatial scales: an example with American marten. Can J Zool 82:1738-1747

Patterson TA, Thomas L, Wilcox C, Ovaskainen O, Matthiopoulos J (2008) State-space models of individual animal movement. Trends Ecol Evol 23:87-94

Potter C (1935) The biology and distribution of Rhyzopertha dominica (Fab.). Trans R Entomol Soc Lond 83:49-482

R Core Team (2014) R: a language and environment for statistical computing. R Foundation for Statistical Computing, Vienna. Available from http://www.R-project.org/

Ripley BD (1988) Statistical inference for spatial processes. Cambridge University Press, Cambridge

Romero SA, Campbell JF, Nechols JR, With KA (2010) Movement behavior of red four beetle: response to habitat cues and patch boundaries. Environ Entomol 39:919-929

Rowlingson B, Diggle P (2013) splancs: spatial and space-time point pattern analysis. R package version 2.01-34. http:// CRAN.R-project.org/package $=$ splancs

Russel JC, Hanks EM, Haran M (2015) Dynamic model of animal movement with spatial point process interactions. J Agric Biol Environ Stat 21:22-40

Russel RW, Hunt GL, Coyle KO, Cooney RT (2017) Foraging in a fractal environment: spatial patterns in a marine predator-prey system. Landscape Ecol 7:195-209

Schooley RL, Wiens JA (2003) Finding habitat patches and directional connectivity. Oikos 102:559-570

Senft RL, Coughenour MB, Bailey DW, Ritten-house LR, Sala OE, Swift DM (1987) Large herbivore foraging and ecological hierarchies. Bioscience 37:789-799

Sih A, Bell A, Johnson JC (2004) Behavioral syndromes: an ecological and evolutionary overview. Trends Ecol Evol 19:372-378

Swihart RK, Slade NA, Bergstrom BJ (2008) Relating body size to the rate of home range use in mammals. Ecology 69:393-399

Turner MG (1989) Landscape ecology: the effect of pattern on process. Annu Rev Ecol Evol Syst 20:171-197 
Turner MG (2005) Landscape ecology: what is the state of the science? Annu Rev Ecol Evol Syst 36:319-344

Utsumi SA, Cangiano CA, Galli JR, McEachern MB, Demment MW, Laca EA (2009) Resource heterogeneity and foraging behavior of cattle across spatial scales. BMC Ecol 9:9

Wiens JA (1995) Landscape mosaics and ecological theory. In: Hansson L, Fahrig L, Merriam G (eds) Mosaic landscapes and ecological processes. Chapman and Hall, London, pp 1-26

Wiens JA, Milne BT (1989) Scaling of "landscapes" in landscape ecology, or, landscape ecology from a beetle's perspective. Landscape Ecol 3:87-96

Wiens JA, Stenseth NC, Van Horne B, Ims RA (1993) Ecological mechanisms and landscape ecology. Oikos 66:369-380

Williams HJ, Silverstein RM, Burkholder WE, Khorramshahi A (1981) Dominicalure 1 and 2: components of aggregation pheromone from male lesser grain borer Rhyzopertha dominica (F.) (Coleoptera: Bostrichidae). J Chem Ecol 7:759-781

With KA (1994a) Ontogenetic shifts in how grasshoppers interact with landscape structure: an analysis of movement patterns. Funct Ecol 8:477-485

With KA (1994b) Using fractal analysis to assess how species perceive landscape structure. Landscape Ecol 9:25-36

With KA, Crist TO (1995) Critical thresholds in species responses to landscape structure. Ecology 79:2446-2459

With KA, Crist TO (1996) Translating across scales: simulating species distributions as the aggregate response of individuals to heterogeneity. Ecol Modell 93:125-137

Wright VF, Fleming EE, Post D (1990) Survival of Rhyzopertha dominica (Coleoptera: Bostrichidae) on fruits and seeds collected from woodrat nests in Kansas. J Kans Entomol Soc 63:344-347 